\title{
The Influence Of Climate Resilient Agriculture On Food Security In Kitui County
}

\author{
Aliseba Akinyi Wagah ${ }^{1}$, Samuel China ${ }^{2}$, Moses Akali, Ngaiwa ${ }^{3}$ and Ferdinand Makhanu Nabiswa ${ }^{4}$ \\ 1,2,3,4 Department of Emergency Management and Humanitarian Assistance, \\ Masinde Muliru University of Science and Technology \\ P.O Box 19050100, Kakamega, Kenya \\ DOI: 10.29322/IJSRP.11.10.2021.p11821 \\ http://dx.doi.org/10.29322/IJSRP.11.10.2021.p11821
}

\begin{abstract}
Climate change and food security are two of the most pressing challenges facing the global community today. Improving smallholder agricultural systems is a key response to both. Given that agriculture is the key economic sector of most low-income developing countries, improving the resilience of agricultural systems is essential for climate change adaptation. Kitui County is characterized by low and declining crop productivity. It is particularly susceptible to climate change due to its over-reliance on rainfed agriculture, aridity, inadequate water supply and degradation of many of its natural resources. This study examined the influence of Climate Resilient Agriculture on food security in Kitui County. The study was underpinned by a theoretical framework guided by the resilience theory and adopted a descriptive research design. The study targeted 384 household heads in Kitui County who included small holder farmers and livestock framers; Stratified random sampling Purposive sampling were used to select the respondents in the study. It was established that Climate Resilience Agriculture had played a significant role to ensure farmers in Kitui are food secure. At least $73 \%$ of the respondents agreed with the statement that 'the adaptation of new variety crops increased food availability and accessibility', while $10 \%$ were not sure and $7 \%$ disagreed with the statement. The overall conclusion of the study is that Climate Resilient Agriculture has led to increased food production and thereby increasing the Food Security, livelihoods, and nutrition in Kitui County. Climate Resilient Agriculture should be embraced by all stakeholders to ensure farmers benefit from the enhancement of the knowledge base to enable them to make informed climate resilience decisions.
\end{abstract}

Key words: Climate Resilient Agriculture, Food Security, Climate Change adaptation, Crop yield, Livelihood

\subsection{Introduction}

The United Nation Framework Convention (UNFCC) defines climate change as a change of climate that is attributed directly or indirectly to human activity that alters the composition of the global atmosphere and that is in addition to natural climate variability observed over comparable time periods (UNFCC, 2011). Extreme weather conditions such as flood and droughts have been experienced globally and this has had a direct effect on food production and thus further impacting on food security. Food security will be increasingly affected by projected future climate change, (IPCC, 2019). According to the World Food Summit, 1996, Food security exists when all people, at all times, have physical and economic access to sufficient, safe and nutritious food that meets their dietary needs and food preferences for an active and healthy life (FAO, 2006). Globally, climatic factors constitute some of the main constraint to food security where livestock and crop production have been assumed as exogenous and unchanging (Wreford et.al., 2010).

Increased temperatures and reduced precipitation can cause important drops in forage production, such as the 60 percent deficit of green fodder during the 2003 summer in France (FAO, 2015). In various countries in sub-Saharan Africa, 20 to 60 percent losses in animal numbers were recorded during serious drought events in the past decades. Over one billion people worldwide live in extreme poverty and livelihood insecurity. More than 75\% are small agricultural producers in rural areas (CORDAID, 2016). 
Kenya is characterized by low and decreasing crop production and like many other developing countries, is especially vulnerable to climate change due to over-reliance on rainfed agriculture, aridity, insufficient water supply and the depletion of many of its natural resources (Briske, 2017).

The Agro-ecological zones in Kenya differ in terms of moisture index, rainfall, vegetation and farming systems, where the arid and semi-arid zones account for about 80 percent of the total land area. Agricultural production has therefore been undermined by unpredictable weather and climate variation, especially in the arid and semi-arid or less arable zones like Kitui County (Mariara \& Kabara 2015). Various organisations have implemented Climate Resilience Agriculture with the aim of employing an integrated approach that increases the productivity and resilience of agricultural systems; consolidate engagement in markets and diversifies income generation; strengthens adaptation to climate change; and increases the ability of local, small scale food producers to access services and influence development policy practices (NCCFP, 2017). Adapting to climate risks is central to the goal of increasing food security and enhancing resilience of farming system. Climate-smart agriculture (CSA) puts the challenges of agricultural development at the heart of transformational change in agriculture by concurrently pursuing increased productivity and resilience for food security (Mwongera, 2018). Producing drought resistant crops such as Cereal legume offer farmers multiple benefits that contribute to increased farm resilience, greater food security and better incomes. Farmers are also taking up soil and water management practices to address the risk of declining rainfall amounts and variability (Recha et al,.2016).

The government and other non-governmental organizations have also begun to roll out educative programmes on climate resistant agriculture with the aim of improving nutrition, climate resilience, yield and stress tolerance of communities in Kitui as a whole (KNA, 2019).

Climate change affects agricultural production and food systems, and thus the approach to transforming agricultural systems. Climate change introduces greater uncertainty and risk among farmers and policymakers (FAO, 2014).

Climate Smart Agriculture (CSA) approach is essential in promoting Climate Resilient Agriculture (CRA) for food security and sustainable livelihoods. It is an approach for developing the technical, policy, and investment conditions to achieve sustainable agricultural development for food security under climate change, (WB, 2016).

Using ICTs is one way of achieving and sustaining sustainable agricultural development and food security (ICT). To manage the climatic risk is of immense importance for protecting livelihoods of small and marginal farmers (Sheokand \& Singh, 2017). Innovation plays an important role in the development of a nation and the strategic application of innovation to the agricultural sector provides the greatest opportunities for economic growth and the alleviation of poverty. Technology helps agricultural stakeholders to make more informed decisions, according to FAO (2018), which in turn makes farming more modern and productive.

\subsection{Theoretical Framework}

This section discussed in detail the resilience theory in relation to the effect of Climate Resilient Agriculture (CRA) on food security.

Resilience can be defined as the capacity of communities, systems, households and individuals to mitigate, prevent or cope with risks and recover from shocks. A system is considered resilient when it is less vulnerable to risks or shocks across time and can effectively recover from them (Turnbull, et al., 2013).

Resilience theory was first described in 1973 by C.S. Holling, who studied how populations function within ecological systems, particularly after some sort of ecological stress. Ecological research prior to Holling's work had been focused on system equilibrium, but Holling argued that a system may have multiple equilibria that it shifts between during stress. In studying predator-prey relationships and population models, Holling noticed that there were multiple stable states possible (Folke, 2014). This realization 
shifted ecological work from focusing solely around a single equilibrium to system unpredictability and more variable behaviours. Thus, from Holling's work, resilience is defined as a system's ability to cope with a stress or shock while preserving its existing function and organization — in other words, without shifting to a new equilibrium (Bahadur, et al., 2013). This resilience perspective shifts the focus from attempting to isolate a system from change to attempting to build the capacity of a system to tolerate change (Folke, 2016).

There is a connection between the organization and behaviour of ecosystems with the organization and behaviour of the people who live in and work with these ecosystems (Greene, 2014). This work stressed the inevitability of uncertainty and began to push environmental management techniques away from the simple "command-and-control" tactics that try to avoid system change. The argument was that these tactics may provide the desired effect in the short term, but as they do not take all variables into account, they can leave systems more vulnerable to disturbances in the long run. This discovery of multiple stable states also led to his work on adaptive ecosystem management and the idea of the adaptive cycle (Holling, 2008).

The adaptive cycle illustrates the degree to which change is an integral part of social ecological systems. Thus, rather than defining resilience based on the ability to maintain a stable stasis, the natural cycle of change needs to be accounted for. The inevitability of changes to the system means that flexibility and adaptability are crucial to a resilient system. This is why definitions of resilience have evolved to incorporate cycles of change, as well as changes from one state of equilibrium to another. Resilient systems, including agro ecosystems, are able to cope with sudden shocks and effectively reorganize, (Prasad, et al., 2015).

A theoretical framework is the visual or written relationship between variables often derived from one or more theories (Saunders, et al., 2016). It is a description of the phenomenon under study accompanied by visual depiction of variables under study.

The theoretical framework for shows the relationship between Climate Resilient Agriculture (CRA) and food security see. Climate Resilient Agriculture is the independent variable and food security is the dependent variable, since food security in Arid and SemiArid Lands (ASALs) mainly depend on Climate Resilient Agriculture. For food security to be achieved in ASALs, CRA should be introduced. However, this process requires the involvement of agricultural stakeholders such as the government, Non-Governmental Organisations and financial institutions (intervening variable), who can ensure food security is achieved by enabling a favourable environment through relevant policy formulation and enactment, financial investments and access to loans and credit facilities, women empowerment as well as initiation of CRA practices. With this, food security in terms of availability, access, stability and utilization will be achieved through increased livelihood options.

\subsection{Methodology}

This study adopted a descriptive research design in order to gain a broader and deeper understanding of the phenomenon under study. A descriptive survey design enabled the researcher to determine the indicators of food security and the influence of Climate Resilient Agriculture on food security.

The target population included household heads in Kitui East sub- county who included small holder farmers and livestock framers; the study population also included key informants who were agricultural stakeholders from both the Government and Nongovernmental organisations.

This study adopted the stratified random sampling technique to select individual respondents, in this case, the smallholder farmers. Stratified random sampling involves dividing the target population into different strata with distinct characteristics and then selecting items randomly from each stratum (Cooper \& Schindler, 2015). The target population was divided into two strata namely, crop farmers and livestock farmers. This was done to ensure that a representative sample from the different farming areas was used. This technique was selected since it ensured all the study components were represented. Additionally, it was affordable in administering research instruments and it was generally applied to obtain a representative sample. Moreover, the study used 
purposive proportionate sampling technique which involved focusing on particular characteristics of a population that are of interest. In this case, the study used purposive sampling in selecting only smallholder farmers who are heads of their households as they were in the best position to explain the food security situation of their households.

This study used a sample size of 384 farmers spread out in the six wards who were obtained by multistage random sampling by use of Equation 1.

$$
n=\frac{Z^{2} p q}{d^{2}} \ldots \ldots \ldots \ldots \ldots . \quad \text { Eqn } 1 .
$$

Where; $n$ - the desired sample size (number of smallholder farmers) if the target population is more than 10,000 (ten thousand).

Z- the standard normal deviation at the required confidence level $(95 \%)$ or $Z=1.96$

p- the proportion in the target population estimated to have the characteristic being investigated in this study is equal to 0.5 $\mathrm{q}=1-\mathrm{p}=0.5$

d- the level of statistical significance required for level precision $(0.05)$

On computation, $n=\frac{(1.96)^{2}(0.5)(0.5)}{(0.05)^{2}}=384.16$, which to the nearest whole number is 384 .

Hence, the sample size used was 384. The Kenya National Bureau of Statistics (KNBS) (2019) suggests that 64\% of farmers in Kitui East are crop farmers and 36\% are livestock farmers. The accurate distribution of livestock and crop farmers which was used in this study is shown in Table 3.1 . 


\subsection{Findings And Discussion}

\section{Influence Of Climate Resilient Agriculture On Food Security In Kitui County}

\subsection{Introduction}

This chapter presents findings from the influence of Climate Resilient Agriculture on food security in Kitui County. The chapter is divided into the following sub-titles: Adoption of new variety of crops and food accessibility; Conservation agriculture and food stability; Effective soil and water conservation strategies and food availability and Efficient application of organic and inorganic fertilizers enhancing food stability.

\subsection{Adoption of new variety of crops and food accessibility}

The statement; 'Adoption of new variety of crops has increased food accessibility in our homes'. The researcher sought to establish whether the cimate smart practices such as adopting new variety of crops such as climate resilient crops has enhanced food accessiblility and food security in general.

The results from the occurrence statement on whether adoption of new variety of crops had increased food accessibility is displayed in Figure 6.1. Out of all the respondents, 64\% and 9\% Agreed and Strongly agreed respectively, while 10\% were Not sure. These results show a higher number of respondents (more than half) agreeing to this statement. This therefore means that adoption of new variety of crops such as Soghum, Millet, Cowpeas and green grams, has indeed improved food accessibility in most households in Kitui County. At least $9 \%$ and $8 \%$ on the other hand Strongly disagreed and Disagreed on the same statement. Due to depressed rainfall occasioned by climate, traditional crops such as maize is no longer a priority for most farmers due to its low returns.

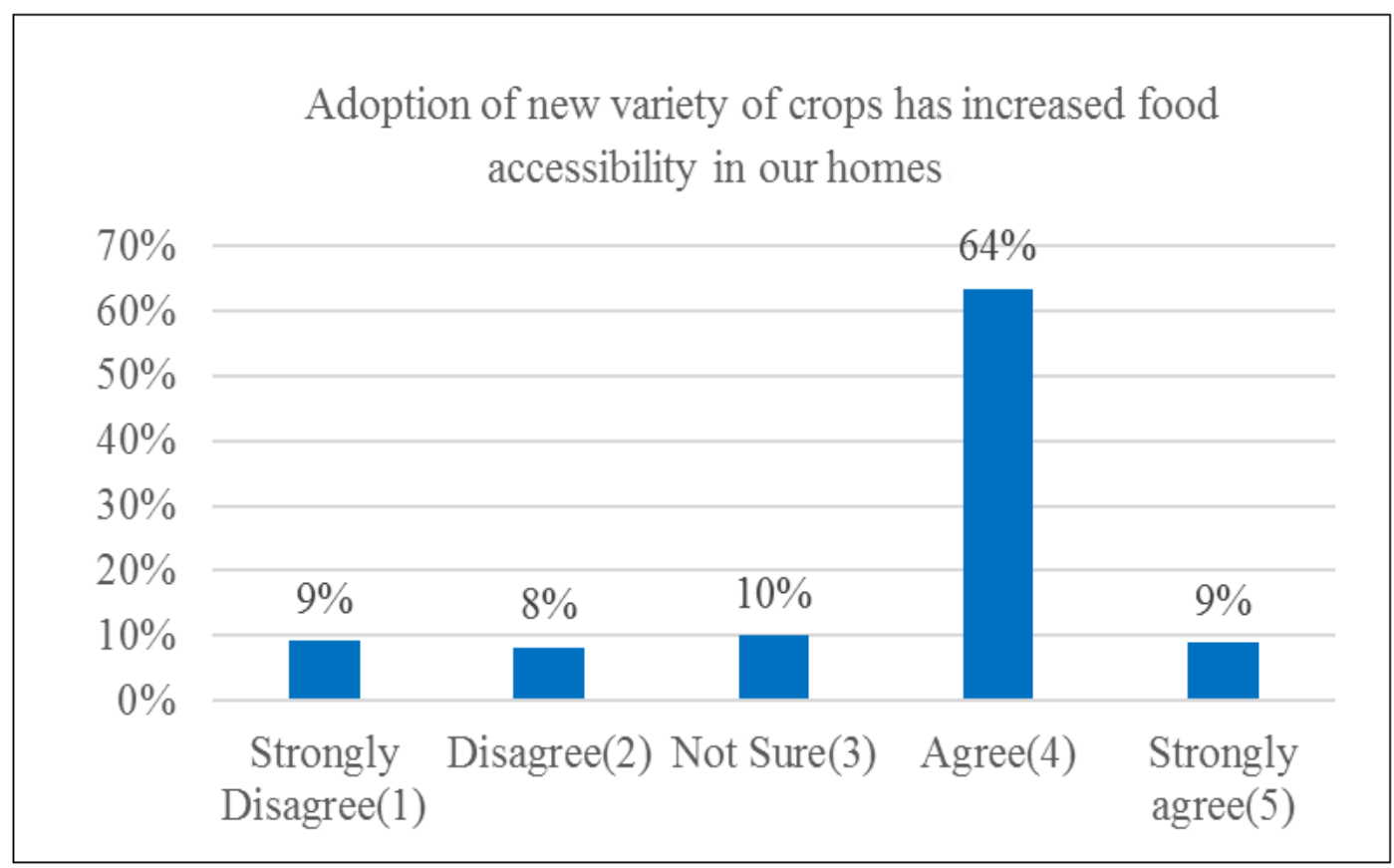

Figure 4.1: Responses to whether the adoption of variety of crops has increased food accessibility in homes

The response on whether adoption of new variety of crops has increased food accessibility in the homes of the respondents for each ward is summarized in Figure 6.2 


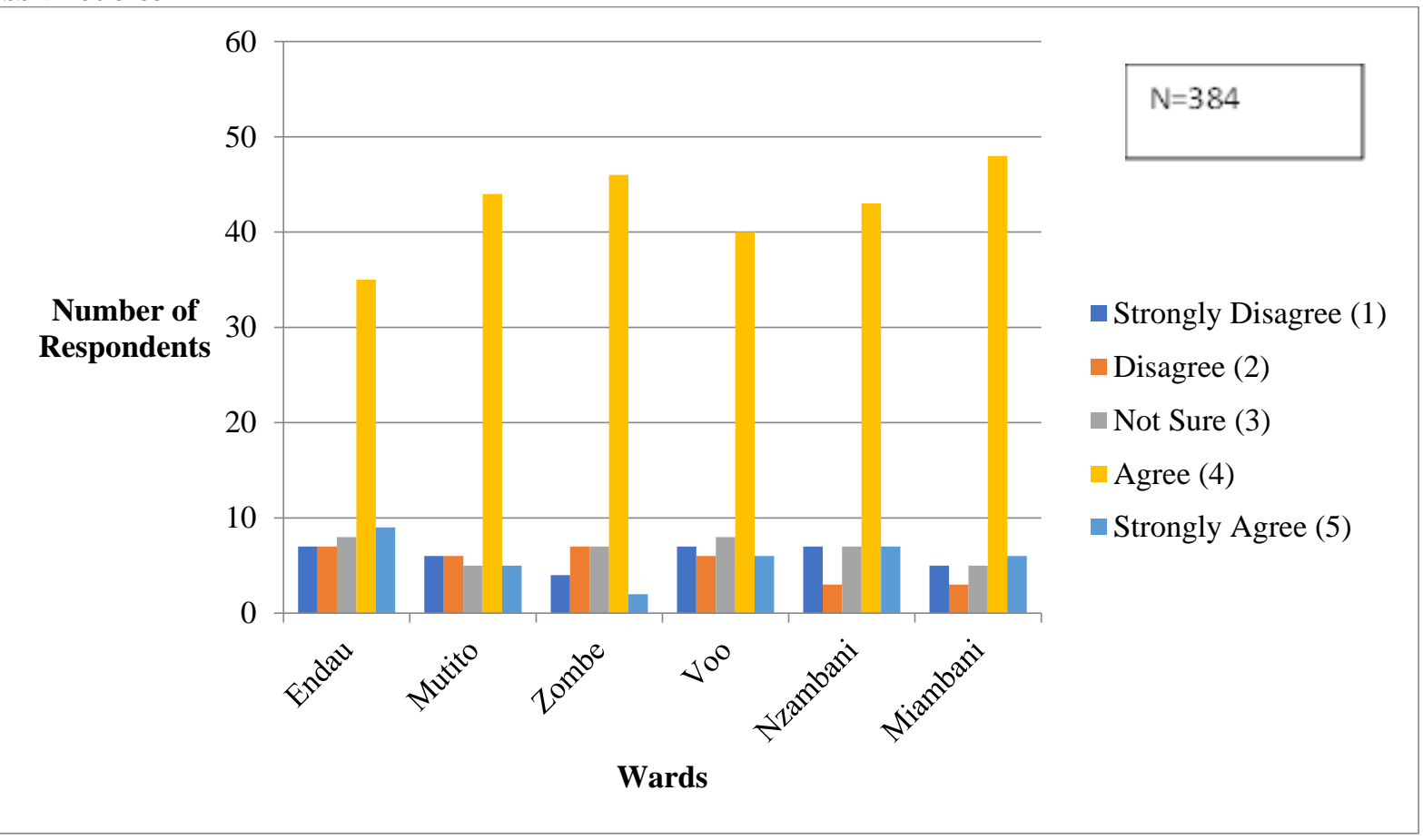

Figure 4.2: Responses to whether the adoption of variety of crops has increased food accessibility in homes per ward

Responses from key informants also revealed that the introduction of resilient crop varieties had indeed helped to address food and nutrition challenges. Disease resistant, pest tolerant, early maturing and high yielding varieties of seeds including sorghum, millet, green grams, cassava, pigeon peas and chick peas had been introduced to farmers in Kitui County by the International Crops Research Institute for the Semi-Arid Tropics (ICRISAT) and the Kenya Agricultural and Livestock Research Organisation (KALRO) as shown in Plate R3. These drought resistant crops have high water-use efficiency and are tolerant to limited soil moisture. Community Based Organisations have also been instrumental in promoting intercrop innovations of that involve these crops. "Our beneficiaries have come to accept and ebarce the new clmate resilient crops such as green grams, peas, millet and cassava, that are fast maturing and are tolerant to harsh climatic conditions. Some practice livestock farming together with crop farming. This ensures that food is available and the household have access to food at all times. Additionally, this has formed a big part of their livelihood".

\subsection{Conservation agriculture and food stability}

In the past 10 years, the government of Kenya together with other agricultural stakeholders has piloted conservation agricultural technology which emphasizes on the significance of creating and maintaining healthy soils and intergarting different approaches to the management of pests, diseases, weeds, and plant nutrients. The adoption of conservation agriculture technology can help crops adapt to climate change and ensure harvests despite unreliable rainfall.

The statement: 'Introduction of conservation agriculture has enhanced food stability in our homes' sought to establish whether smallholder farmers had benefitted from conservation agriculture introduced by the government and other stakeholders. The responses for this statement are presented in Figure 6.3. Out of all the respondents, 55\% agreed, 17\% strongly agreed, while 14\% were not sure and $3 \%$ and $11 \%$ strongly disagreed and disagreed respectively. 


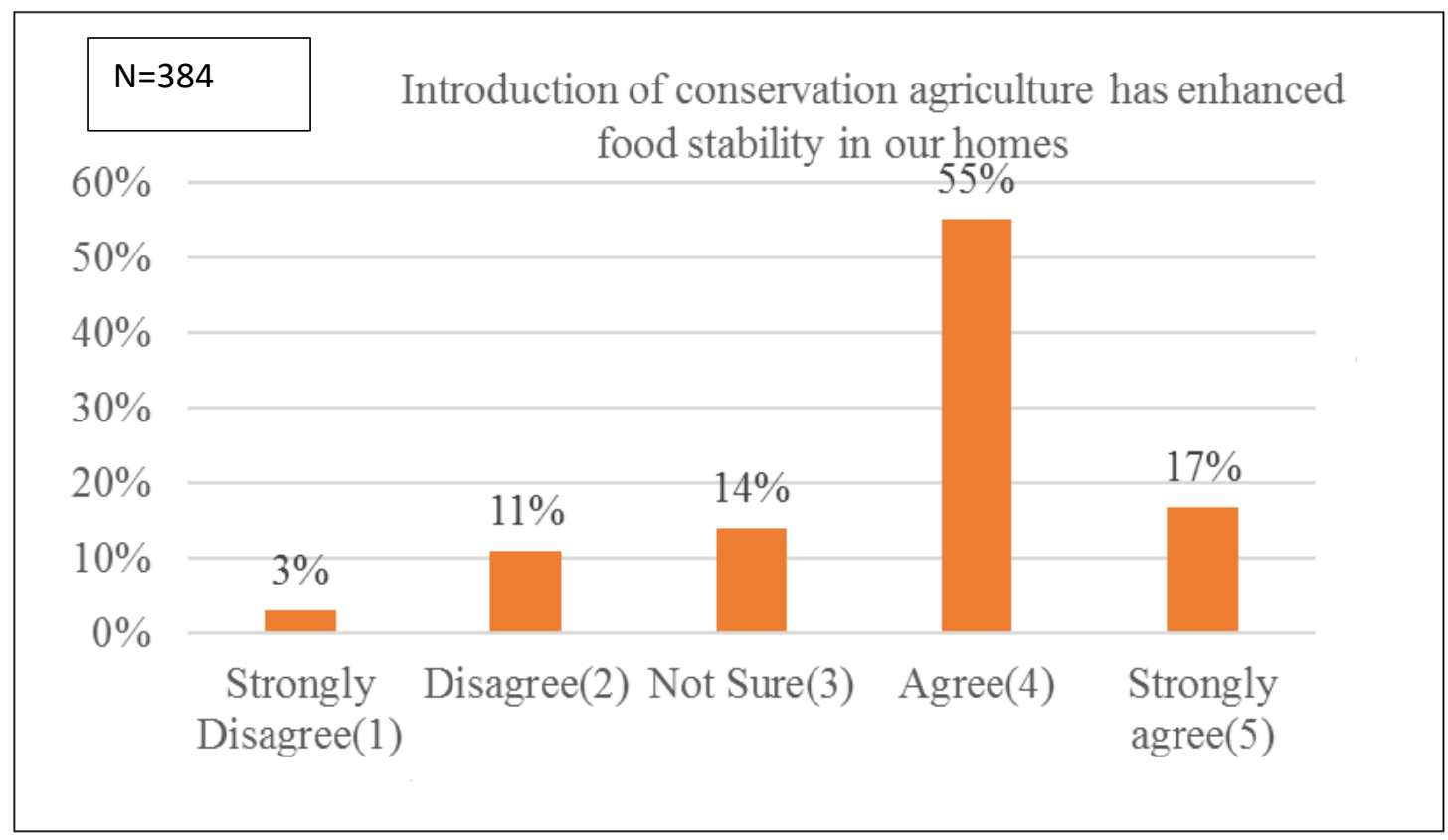

Figure 4.3: Responses to whether the introduction of conservation agriculture has enhanced food stability in homes

Responses on whether introduction of conservation agriculture has enhanced food stability in Kitui East sub county for each ward is summarized in Figure 6.4

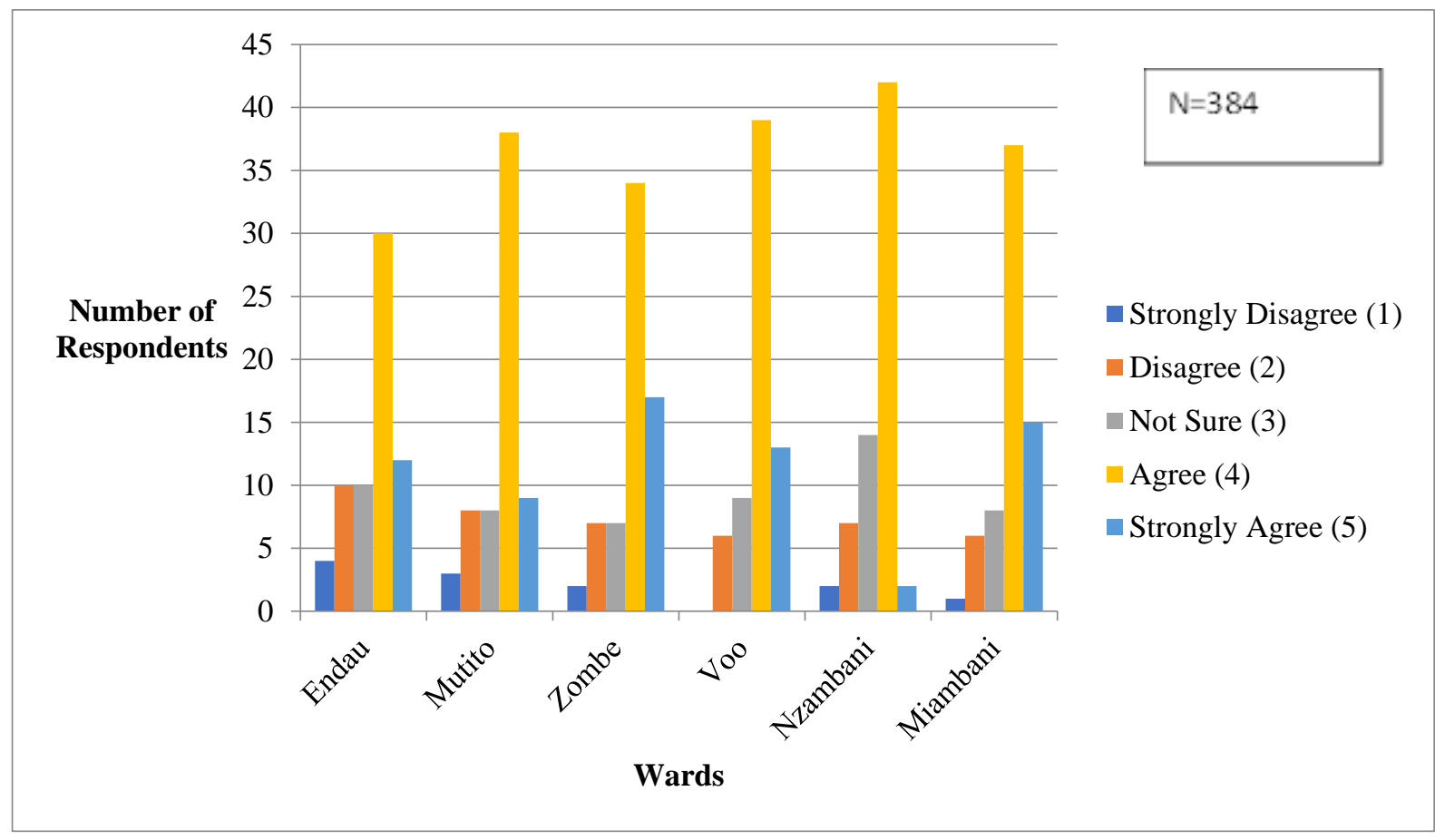

Figure 4.4: Responses to whether the introduction of conservation agriculture has enhanced food stability in homes per ward

It was evident that smallholder farmers practiced conservation agriculture. Responses from local chiefs also revealed that most smallholder farmers had embraced conservation agriculture. One of the chiefs, who is also a smallholder farmer admitted that he had been planting maize for a long time and often got barely enough harvests for his family. He said he had heard about conservation 
agriculture practices but was hesistant to try them. However, when he adopted conservation agriculture practices in 2014, his yields increased from two to five bags when he harvests. This is one example of how conservation agriculture has benefitted small holder farmers in Kitui County.

\subsection{Effective soil and water conservation strategies and food availability}

For the sustainability of livelihoods, effective soil and water conservation strategies are mandatory. The use of conservation strategies in agricultural production is determined by the various income-earning strategies themselves and together with some of the socio-economic and biophysical conditions (Jansen et al., 2006). To enhance food security, including food availability, productivity and production is mandatory. Productivity and conservation objectives go hand in hand, since conservation of soil, water and natural vegetation leads to higher productivity of crops as well as livestock and thus food security.

The statement; 'Effective soil and water conservation strategies resistant to climate shocks has increased food availability in out homes', sought to establish whether smallholder farmers had indeed benefitted from soil and water conservation strategies. The responses for this statement are summarised in Figure 6.5. No less than $42 \%$ and $31 \%$ of the respondents agreed to the statement while $14 \%$ were not sure and 5\% and $9 \%$ respectively strongly disagreed and disagreed to the same. From the responses, it was evident that these effective soil and water conservation strategies had enhanced food availability in homes.

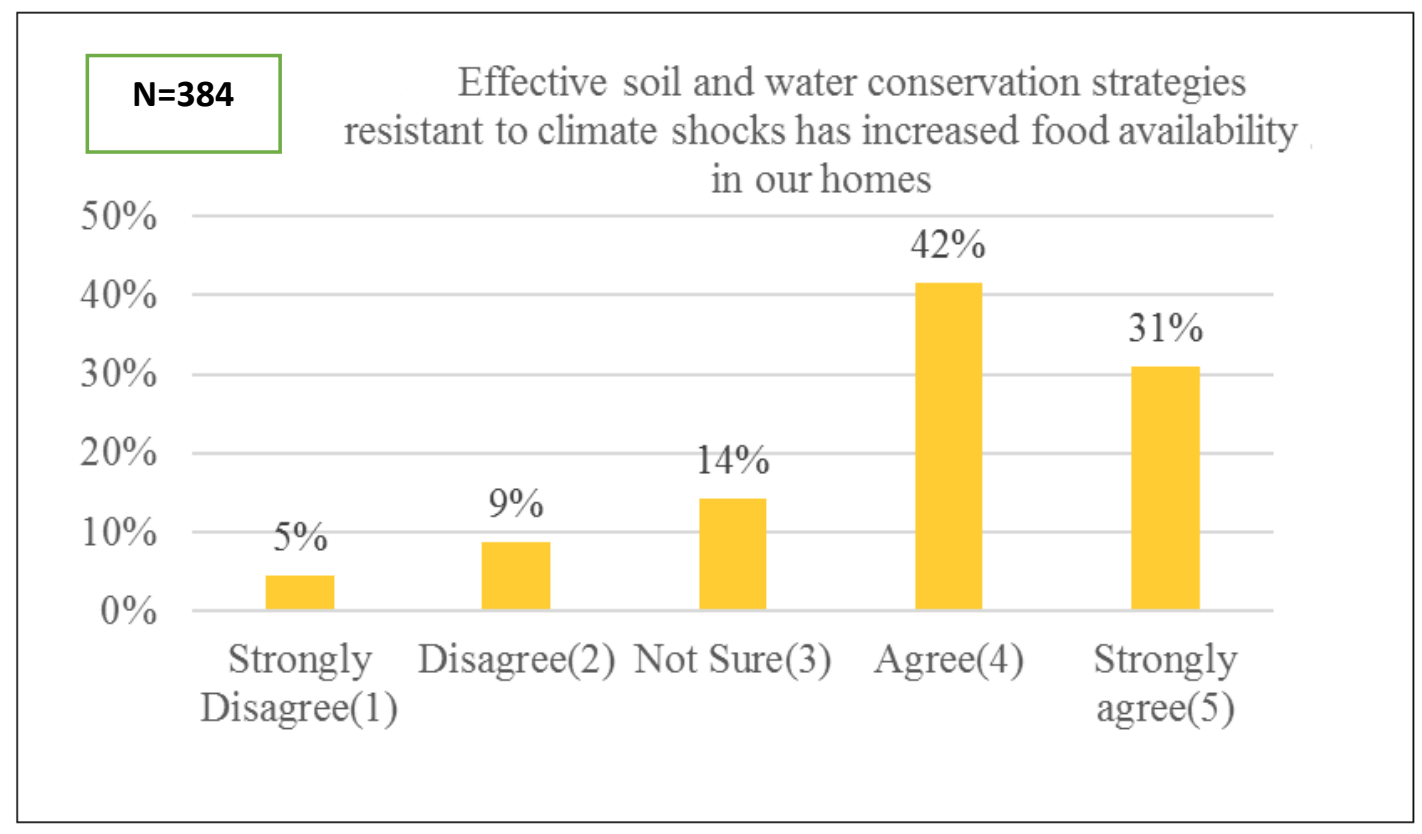

Figure 4. 5: Responses to whether effective soil and water conservation strategies resistant to climate shocks has increased food availability in homes

The responses on whether effective soil and water conservation strategies resistant to climate shocks has increased food availability for the respondents in different wards are summarized in Figure 6.6 


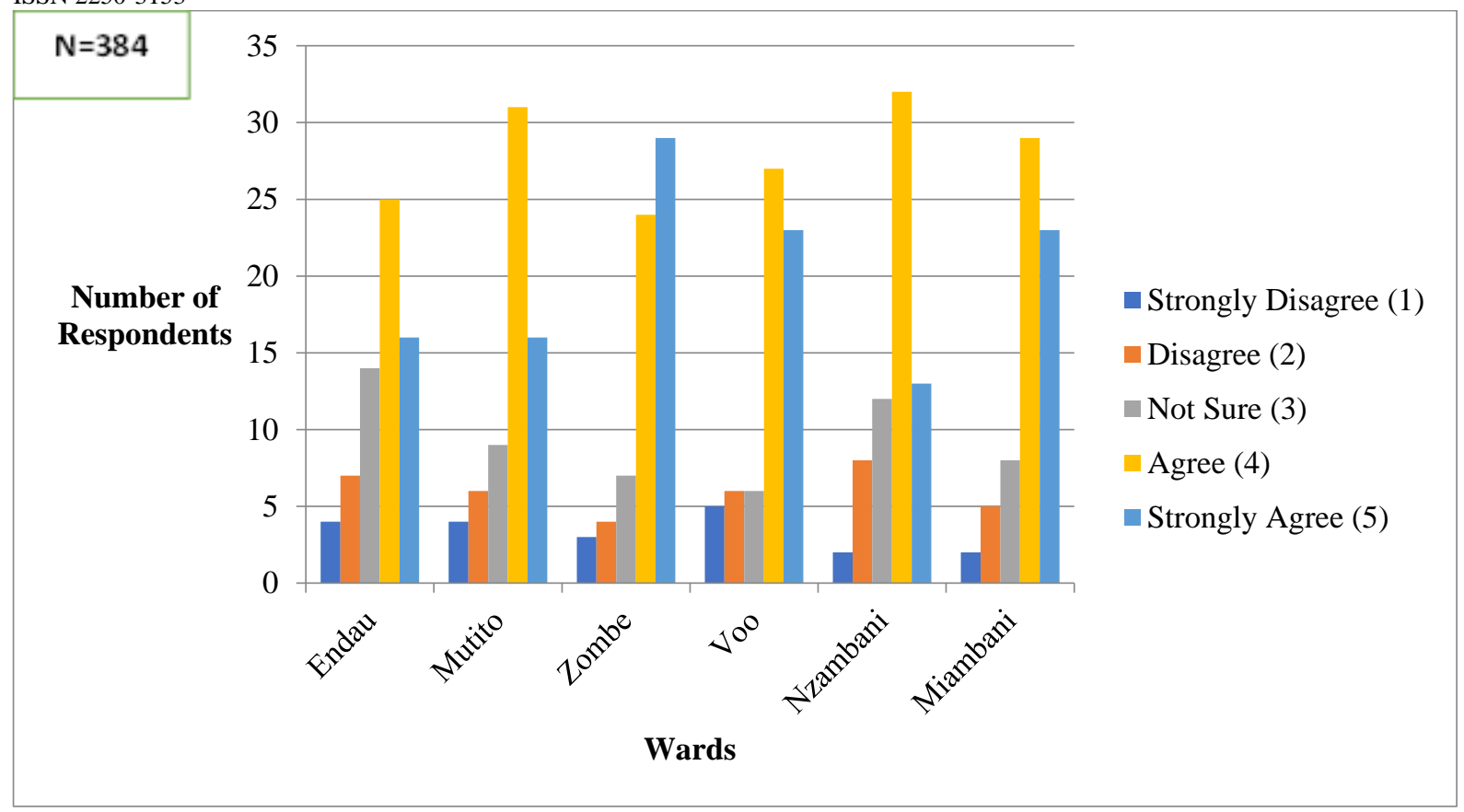

Figure 4. 6: Responses to whether effective soil and water conservation strategies resistant to climate shocks has increased food availability in homes per wards

During data collection, it was evident that various smallholder farmers in the study area had adopted soil and water conservation strategies. An interview with the a local chief also revealed that to address the risk of the decline in rainfall variability, smallholder farmers were taking up different soil and water management practices. These include water harvesting using different storage structure and water management strategies for the replenishment of soil moisture. Some of the land management practices for retaining soil moisture that were evident during data collection include cut-off drains, retention ditches, artificial waterways, and planting pits as shown in Plate R4. In support of these findings one of the key informants opined that:

Over time, I have seen farmers make substantial investments on their land. Such investments include terracing, application of manure, planting of trees, among others. These investments conserve water and the soils at the farm household level and improving on the quality and quantity of yied produced. (An interview with a local government administrator in Miambani on $7^{\text {th }}$ January 2021)

\subsection{Efficient application of organic and inorganic fertilizers enhancing food stability}

The statement; 'Efficient application of organic and inorganic fertilizers has enhanced food stability in our homes', sought to establish whether the indeed efficient application of organic and inorganic fertilizers have indeed benefitted small holder farmers in Kitui County. The responses for this statement are presented in Figure 6.7. At least $45 \%$ and $31 \%$ of the respondents agreed and strongly agreed respectively while $10 \%$ were not sure and $3 \%$ and $10 \%$ strongly disagreed and disagreed to the statement. This shows that most farmers acknowledged that indeed efficient application of organic and inorganic fertilizers had enhanced food 


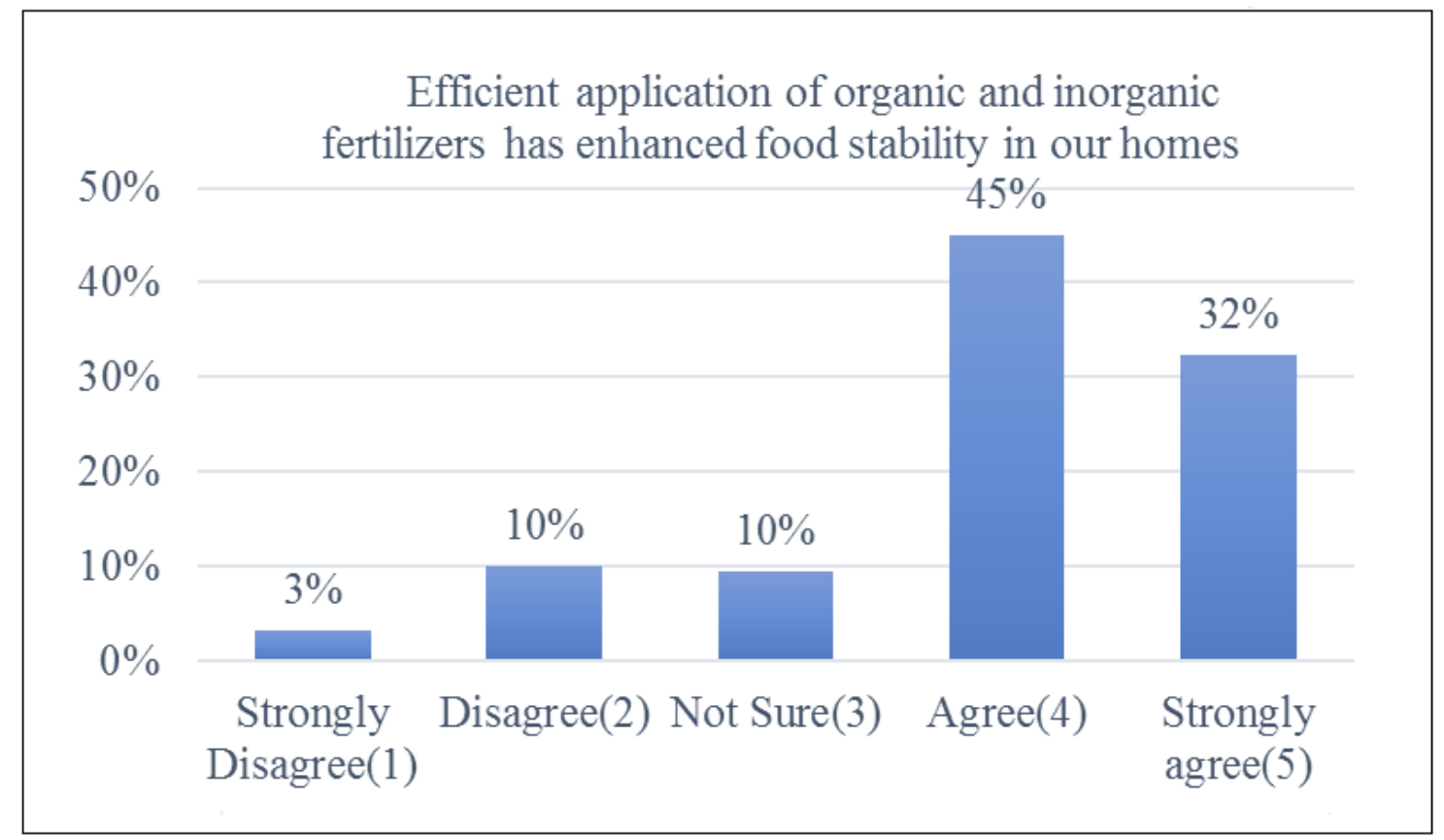

Figure 4. 7: Responses to whether efficient application of organic and inorganic fertilizers has enhanced food stability in homes

Responses per ward for whether efficient application of organic and inorganic fertilizers has enhanced food stability in homes is summarized in Figure 6.8

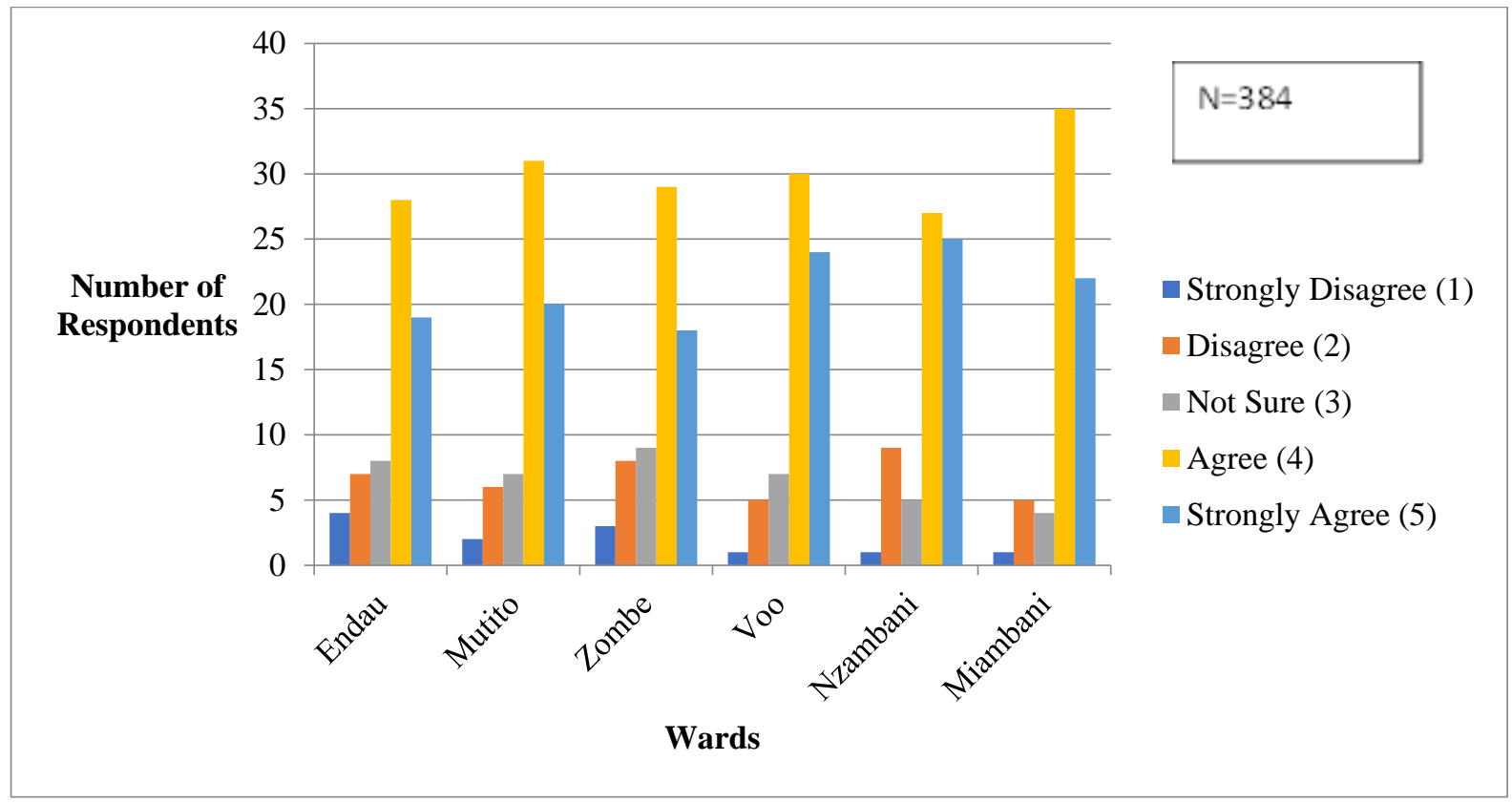

Figure 4. 8: Responses to whether efficient application of organic and inorganic fertilizers has enhanced food stability in homes per ward.

The findings for the households were further supported by Key informants one of who reitertated that: 
We have been training our farmers on the importance of using organic fertilizers in the soil. This is because right now we have organic fertilizers in the market that can be used to grow any kind of crop and give very high yield. Combined with other methods such ass minimum tillage, it is ery easy to maintain soil fertility and manage soil erosion ( An interview with an extension officer in Endau on $6^{\text {th }}$ January 2021).

The findings of this study are in agreement with (Mikkelsen, 2020) who opined that A survey of U.S. crop production estimated that average corn yields would decline by 40 percent without nitrogen $(\mathrm{N})$ fertilizer. Even greater declines would occur if other macronutrients, phosphorus $(\mathrm{P})$ and potassium $(\mathrm{K})$ were also limited. Numerous long-term studies have also demonstrated the contributions of fertilizer to sustaining crop yields. In this regard, the role of mature in food production is important and as such cannot be ignored.

\subsection{Chapter Summary}

The chapter has presented findings and discussions on the influence of Climate Resilient Agriculture on food security in Kitui County. The findings of these chapter have been key in understanding the various strategies employed in in Climate Resilient Agriculture to deal with the issues of food security. Among the strategies discussed include; Adoption of new variety of crops and food accessibility; Conservation agriculture and food stability; Effective soil and water conservation strategies and food availability and Efficient application of organic and inorganic fertilizers enhancing food stability. The next Chapter (Chapter seven) which is the final chapter of this thesis gives presents the summary, conclusions and recommendations of this study.

\subsection{Summary}

The chapter has presented findings and discussions on the influence of Climate Resilient Agriculture on food security in Kitui County. The findings of these chapter have been key in understanding the various strategies employed in in Climate Resilient Agriculture to deal with the issues of food security. Among the strategies discussed include; Adoption of new variety of crops and food accessibility; Conservation agriculture and food stability; Effective soil and water conservation strategies and food availability and Efficient application of organic and inorganic fertilizers enhancing food stability.

\subsection{Conclusion}

Climate Resilient Agricultural practices have an influence on food security in Kitui county. Various CRA practices adopted by stakeholders have been key in supplementing food requirements at both household and community level and as such helped in improving the food security situation in the county.

\subsection{Recommendation}

Agricultural stakeholders in both governmental and non-governmental organisations should ensure that every farmer in each ward is included in Climate Resilient Agricultural projects when in comes to training on these practices or accessing funds or even climate resilient seeds. This is because in as much as most of the respondents suggested they were food secure, a few were not. Stakeholders 
should therefore strive to reach every farmer they could use local chiefs to mobilize people during meetings on trainings or any other agenda. Suggestions for Further Study

From the study it was evident that there was limited agricultural training and agricultural extension services. An elaborate study on the status and efficiency of agricultural training and extension services could be essential to policymakers on the approach they could take in developing agricultural livelihoods. In addition, a comparative analysis should also be done to establish the differences in food security, nutritional status and income gains in households from ASAL and non- ASAL areas.

\section{References}

Wreford, A., Dominic, M.., Neil, A. (2010). Climate Change and Agriculture: Impact, Adaptation and Mitigation. Organization for Economic Cooperation and Development, 2010

Briske, D. D. (2017). Range land systems: Process, management and challenges. Springer series on Environmental Management

Catholic Organization for Relief and Development Aid (CORDAID) (2016). Food Security and Climate Resilient Approach in Kenya.

Cooper, D., Schindler, P. (2011). Business Research Methods. 12th Edition, McGraw Hill, Boston.

Folke, C. (2016). Resilience. Ecology and Society 
Food and Agriculture Organisation (FAO) (2014). Climate-smart agriculture sourcebook. Food and Agriculture Organization of the United Nations, 2014.

Food and Agriculture Organisation (FAO) (2006). Food security policy brief. Food and Agriculture Organization of the United Nations, 2006.

Food and Agriculture Organisation (FAO) (2015). Climate change and food security: risks and responses. Food and Agriculture Organization of the United Nations, 2015.

Food and Agriculture Organisation (FAO) (2018). World food and Agriculture: Statistical pocket book 2018. Food and Agriculture Organization of the United Nations, 2018.

Greene, R. (2014) Resilience as effective functional capacity: An ecological stress model.

Holling, C, F and Craig, R. (2008). Discontinuities in ecosystems and other complex systems.

Intergovernmental Panel on Climate Change (IPCC) (2019): Summary for Policymakers. In: Climate Change and Land: an IPCC special report on climate change, desertification, land degradation, sustainable land management, food security, and greenhouse gas fluxes in terrestrial ecosystems.

Kenya News Agency (KNA) (2019) Kitui launches climate change adaptation fund. https://www.kenyanews.go.ke/kituilaunches-climate-change-adaptation-fund/

Kenya National Bureau of Statistics (KNBS) (2019). Kenya National Bureau of Statistics (KNBS) (2013). 2019 Kenya Population and Housing Census Volume I: Population by County and Sub-County.

Mariara, J.K., Kabara, M. (2015). Climate change and food security in Kenya. Paper Submitted for CSAE Conference 2014, Nairobi, Kenya.

The National Climate Change Framework Policy (NCCFP) (2017). Sessional Paper No. 5 of 2016 on National Climate Change Framework Policy.

Mikkelsen, R. (2020). Nutrient Management for organic farming.

Mwongera, C. (2018). Making Climate-Smart Agriculture Work For Africa's farmers - Farming First. Retrieved 24 January 2020, from https://farmingfirst.org/2018/12/climate-smart-agriculture-africa/

Prasad, V., Tanner, T.M., Lewis, D., Wrathall, D., Bronen, R., Cradock-Henry, N., Huq, S., Lawless, C., Nawrotzki, R., Rahman, M.A., Alaniz, R. (2015) Livelihood resilience in the face of climate change, Nature Climate Change 5: $23-26$.

Turnbull, M., Charlotte, L., Sterret, A. (2013) Toward resilience. A guide to Disaster Risk Reduction and Climate Change Adoptation

Recha, J., Radeny, M., Kimeli, P., Atakos, V., Kisilu, \& R., Kinywee, J. (2016). Building Adaptive Capacity and Improving Food Security in Semi-Arid Eastern Kenya. CCAFS Info Note. Copenhagen, Denmark.

Saunders, C., Ulrin, R., Magnus, M., Martin, W. (2016). Control configuration and control enactment in information systems projects: Review and expanded theoretical framework.

Sheokand, R,. Singh, S. (2017). ICT tools for Climate Resilient Farming.

United Nations Framework Convention on Climate Change (UNFCC) (2011). Fact sheet: Climate change science - the status of climate change science today. 
